\title{
Aspartate modulates the ethanol-induced oxidative stress and glutathione utilizing enzymes in rat testes
}

\author{
Se In Oh${ }^{1}$, Mee Sook Lee ${ }^{2}$, Cho-II Kim ${ }^{3}$, \\ Kye Yong Song ${ }^{4}$ and Sang Chul Park ${ }^{5,6}$ \\ ${ }^{1}$ Department of Food \& Nutrition, Seoil College, Seoul 131-702, \\ Korea \\ ${ }^{2}$ Department of Food \& Nutrition, Hannam University, Taejon 306- \\ 791 , Korea \\ ${ }^{3}$ Nutrition Research Team, Korea Health Industry Development \\ Institute, Seoul 156-050, Korea \\ ${ }^{4}$ Department of Pathology, Chung Ang University College of Medi- \\ cine, Seoul 156-756, Korea \\ ${ }^{5}$ Department of Biochemistry, Seoul National University College of \\ Medicine, Seoul 110-799, Korea \\ ${ }^{6}$ Corresponding author: Tel, +82-2-740-8244; \\ Fax, +82-2-744-4534; E-mail, scpark@snu.ac.kr
}

Accepted 19 February 2002

Abbreviations: TBARS, thiobarbituric acid reactive substances; GPx, glutathione peroxidase; GR, glutathione reductase; G6PDH, glucose-6-phosphate dehydrogenase; GST, glutathione transferase

\begin{abstract}
In order to develop a preventive strategy against ethanol-induced oxidative damages on various tissues and organs, we have examined the protective effect of aspartate on the pathogenesis of testes in the ethanol treated animals. Adult male SpragueDawley rats were given ethanol in an amount of $36 \%$ of total calories via Lieber-DeCarli liquid diet for 6 weeks without or with aspartate (2 $\mathrm{mM}$ in the diet). The control group was pair-fed the diet containing isocaloric dextrin-maltose instead of ethanol. The pathogenesis of testes at post- 6 weeks of experiments were carried out by histochemistry and biochemical parameters for oxidative stress such as the level of thiobarbituric acid reactive substances (TBARS) and the activities of glutathione utilizing enzymes were also examined. Chronic ethanol administration resulted in the increased amount of thiobarbituric acid reactive substances (TBARS) in the testes, which was significantly lessened by concurrent aspartate treatment $(p<0.05)$. In addition to this, liver function test indicated by alkaline phosphatase activity in serum showed that the ethanolinduced hepatotoxicity was significantly ameliorated by aspartate administration. And the activities
\end{abstract}

of glucose-6-phosphate dehydrogenase and glutathione transferase in testis cytosol were decreased in the ethanol treated rats $(p<0.01$ and $<0.005$, respectively). These data suggest that aspartate may attenuate the ethanol-induced oxidative tissue damage in rat testes possibly through a redox-related protective effect on peroxidation.

Keywords: Aspartate, Oxidative stress, TBARS, Glutathione, Testes

\section{Introduction}

Alcohol abuse leads to testicular lipid peroxidation (Rosenblum et al., 1989), which may be responsible for ethanol-induced testicular toxicity. Testicular mitochondrial membranes enriched with polyunsaturated lipids, may be the principally affected sites for putative peroxidation injury and contribute to the testicular membrane injury, resulting in gonadal dysfunction, common in alcohol abuse and/or chronic use (Villalta et al., 1997). Rosenblum et al. (1985) suggested that the ethanolinduced oxidative damage can be more prominent in testes than liver tissues, because of a rapid depletion of testicular glutathione by ethanol and lower activities of antioxidant enzymes in this organ (Peltola et al., 1992).

The increased cytosolic NADH/NAD ratio in ethanol oxidation steps would induce conversion of xanthine dehydrogenase $(\mathrm{XDH})$ to xanthine oxidase $(\mathrm{XO})$ facilitating generation of free radicals (Engerson et al., 1987). Thus, lowering the level of cytosolic NADH would expedite ethanol oxidation and reduction of free radial formation. Aspartate has been demonstrated to restore the cytosolic NADH/NAD ratio and improve the functional recovery either from ischemia/reperfusion injury or from ethanol-induced toxicity in the liver (Park and Park, 1995; Park et al., 1998). In this study, testes were chosen for a possible target organ for the ethanol-induced oxidative cellular damages and was examined the protective effect of aspartate by modulating the redox potential. Examination of the pathologic changes and biochemical parameters for oxidative stress such as level of thiobarbituric acid reactive substances (TBARS) and the activities of glutathione utilizing enzymes showed that there were significant differences on biochemical parameters for oxidative stress between the treated and control groups and addition of aspartate attenuated such oxidative tissue damages. 


\section{Materials and Methods}

\section{Animals}

Weanling male Sprague-Dawley rats were fed standard laboratory rat chow (Samyang, Seoul, Korea) and water until $120-180 \mathrm{~g}$ of body weight was reached. Then the rats were divided into weight-matched pairs and allocated to the respective experimental groups (4 groups of 6 animals each: $2 \times 2$ factorial design). They were housed in the individual stainless steel wire-bottomed cages and kept at $22-25^{\circ} \mathrm{C}$ with $12 \mathrm{~h}$ light/dark cycle. All animal procedures and handling were in compliance with the Seoul National University Guidelines for handling and care of experimental animals.

\section{Experimental design}

Rats in ethanol group were given the Lieber-DeCarli liquid diet containing $36 \%$ of energy as ethanol ad libitum (with or without $2 \mathrm{mM}$ aspartate in the diet), and the pair-fed control animals received isocaloric amount of diet (with or without $2 \mathrm{mM}$ aspartate) containing dextrin-maltose instead of ethanol on following day. Ethanol was introduced into the diet gradually starting from $0 \%$ and increasing to final $5 \%$ in one week period. On the 41 st day of experiment, rats were given the diet in two half portions, one in the morning and the other in the evening. The animals were put in euthanasia on the following morning by decapitation. Non-liquid component of the diet was supplied by Dyets Inc. (Bethelehem,

Table 1. Composition of liquid diet for rat

\begin{tabular}{lc}
\hline \multirow{2}{*}{ Component } & Concentration \\
\cline { 2 - 2 } & g/liter (1000 kcal liquid diet) \\
\hline Casein & 41.4 \\
L-Cystine & 0.5 \\
DL-Methionine & 0.3 \\
Corn oil & 8.5 \\
Olive oil & 28.4 \\
Safflower oil & 2.7 \\
Dextrin maltose & $115.2^{1)}$ \\
Choline bitartrate & 0.53 \\
Fiber & 10.0 \\
Xanthan gum & 3.0 \\
Vitamins and minerals &
\end{tabular}

1) In the ethanol formula, replaced by $25.6 \mathrm{~g}$ of dextrin maltose and $50 \mathrm{~g}$ of ethanol.

2) Vitamins (/1000 kcal) : thiamin hydrocholride, $1.5 \mathrm{mg}$; riboflavin, $1.5 \mathrm{mg}$; pyridoxine hydrochloride, $1.75 \mathrm{mg}$; nicotinic acid, $7.5 \mathrm{mg}$; calcium pantothenate, $4.0 \mathrm{mg}$; folic acid, $0.5 \mathrm{mg}$; biotin, $50 \mu \mathrm{g}$; vitamin B12, $25 \mu \mathrm{g}$; p-aminobenzoic acid, $12.5 \mathrm{mg}$; inositol, $25 \mathrm{mg}$; vitamin A, $6000 \mathrm{IU}$; vitamin D, $400 \mathrm{IU}$; vitamin E, $30 \mathrm{IU}$; and vitamin K, $125 \mu \mathrm{g}$. Minerals (mg/1000 kcal): calcium, 1300; phosphorus, 1000; sodium, 255; potassium, 900; magnesium, 125; manganese, 13.5; iron, 8.8; copper, 1.5; zinc, 7.5; iodine, 0.05; selenium, 0.025; chromium, 0.5; chloride, 390; sulfate, 250; and fluoride, 0.25 .
PA, USA) and prepared with $d-\mathrm{H}_{2} \mathrm{O}$ and/or ethanol everyday according to the compositions. The composition of liquid diet is shown in Table 1.

\section{Sample preparation}

Blood was taken from the neck vessels and let stand for $30 \mathrm{~min}$ at room temperature. Serum was obtained by centrifugation at $1000 \mathrm{~g}$ for $20 \mathrm{~min}$ and stored at $-70^{\circ} \mathrm{C}$ in aliquots until analysis. Testes were homogenized with glass/Teflon homogenizer. Testis homogenates were prepared with 9 volumes of ice cold $11.5 \mathrm{~g} / \mathrm{L} \mathrm{KCl}$ with 0.2 $\mathrm{mmol} / \mathrm{L}$ phenylmethylsulfonylfluoride (PMSF) and $1 \mathrm{mmol} /$ $\mathrm{L}$ dithiothreitol (DTT) using up and down strokes and filtered through 3 layers of gauze to remove connective tissues. Cell debris and nuclei were removed by centrifugation at $800 \mathrm{~g}$ for $10 \mathrm{~min}$. The supernatant, a suspension of mixed and preserved organelles, was centrifuged at $13,200 \mathrm{~g}$ for $10 \mathrm{~min}$. The post-mitochondrial $(13,200 \mathrm{~g})$ supernatant was centrifuged again at 105,000 $\mathrm{g}$ for $60 \mathrm{~min}$ to separate cytosol from microsomal fractions. Then, the supernatant fractions (cytosol) were recentrifuged at $105,000 \mathrm{~g}$ for another $30 \mathrm{~min}$ to reduce cross contamination. The cytosol fractions were stored at $-70^{\circ} \mathrm{C}$ in aliquots. The whole procedure was carried out at $0-4^{\circ} \mathrm{C}$.

\section{Histological analysis}

Testis from each animal was fixed in formalin as a whole, embedded in paraffin and sections were cut in $6 \mathrm{~mm}$ thickness. Each section was stained with hematoxylin and eosin (Lee, 1960). The testes were evaluated histologically for the cross sectional size variation of seminiferous tubules.

\section{Biochemical parameters of liver function}

Activities of alkaline phosphatase (ALP) and lactate dehydrogenase (LDH), and the serum levels of uric acid (UA), cholesterol ( $\mathrm{CHO})$, total protein (TP), total bilirubin (TBIL) and direct bilirubin (DBIL) were measured in serum by Technicon autoanalyzer (Technicon Inc. NY). Activities of aspartate aminotransferase (AST) and alanine aminotransferase (ALT) in serum were measured using commercially available diagnostic kits (No. 58-20 and No. 59-20; Sigma Chemical Co., St. Louis, MO, USA).

\section{Thiobarbituric acid reactive substances (TBARS)}

The content of 2-thiobarbituric acid reactive substances (TBARS) in the testis homogenate was measured as a marker of lipid peroxidation by the method of Uchiyama and Mihara (1978) using 1,1,3,3-tetraethoxypropane (TEP) as a standard. Absorbance of butanol phase was read at 535 and $520 \mathrm{~nm}$ against $\mathrm{n}$-butanol. The difference was used in calculation of TBARS content against that of 1,1,3,3-TEP. 


\section{Enzymatic assays}

Glutathione peroxidase (GPx) in the testis cytosol was assayed in $50 \mathrm{mM}$ Tris, $0.1 \mathrm{mM}$ EDTA buffer $(\mathrm{pH} 7.6)$ by measuring the oxidation of NADPH at $340 \mathrm{~nm}$ with cumene hydroperoxide as a substrate (Tappel, 1978). Glutathione reductase (GR) in the testis cytosol was assayed in $0.2 \mathrm{M}$ potassium phosphate buffer, $\mathrm{pH} 7.0$ by monitoring the oxidation of NADPH at $340 \mathrm{~nm}$ with GSSG as a substrate (Carberg and Mannervick, 1985). Glucose-6-phosphate dehydrogenase (G6PDH) activity in the testis cytosol was measured at $25^{\circ} \mathrm{C}$ according to Löhr and Waller (1974). Assay of glutathione transferase (GST) activity in the testis cytosol was performed in phosphate buffer, $\mathrm{pH} \mathrm{6.5,} \mathrm{using} \mathrm{1-chloro-2,4-dinitroben-}$ zene (CDNB) as a substrate and the absorbance change was recorded at $340 \mathrm{~nm}$ (Harbig et al., 1985). The activity was calculated using extinction coefficient of 9.6 $\mathrm{mM}^{-1} \cdot \mathrm{cm}^{-1}$.

\section{Protein assay}

Proteins were assayed with the Bradford method (1970) using bovine serum albumin as a standard.

\section{Statistical analysis}

Data were expressed as mean \pm standard error of the mean (SEM). Two-way analysis of variance was performed to determine the effect of ethanol, aspartate and their interaction. And statistical significance of the difference among group means was determined by Duncan's multiple range test.

\section{Results}

In spite of the similar food intake provided by pair feeding, ethanol-fed rats gained less body weight than pairfed controls during the study period $(2.22 \pm 0.20$ vs 3.05

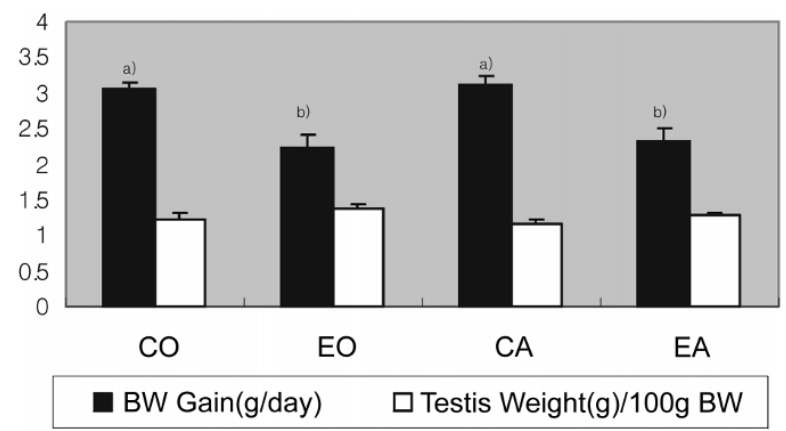

Figure 1. Effect of chronic ethanol consumption with and without aspartate on body weight gain and weight changes of testes. Each value represents the mean \pm SEM of 6 rats. Means with same superscript are not significantly different at $p<0.05$ by Duncan's multiple range test. Abbreviations used for treatments are as follows: $\mathrm{CO}=$ pair-fed control diet; $\mathrm{EO}=$ ethanol diet; $\mathrm{CA}=$ pair-fed control diet + aspartate treatment; $\mathrm{EA}=$ ethanol diet + aspartate treatment.
Table 2. Effect of chronic ethanol administration with or without aspartate on cross-sectional area of seminiferous tubules

\begin{tabular}{lc}
\hline Groups & $\begin{array}{c}\text { The area of seminiferous } \\
\text { tubules }\left(\times 10^{4} \mu \mathrm{m}^{2}\right)\end{array}$ \\
\hline CO $^{1)}$ & $2.08 \pm 0.04^{2)}$ \\
EO & $2.19 \pm 0.04$ \\
CA & $2.22 \pm 0.07$ \\
EA & $2.33 \pm 0.01$ \\
Significance level of effect by 2 -way & ANOVA \\
Ethanol & NS \\
Aspartate & NS \\
Interaction & NS
\end{tabular}

1) Abbreviations used for treatments are as follows: $\mathrm{CO}=$ pair-fed control diet;

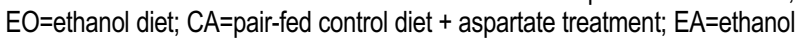
diet + aspartate treatment.

${ }^{2)}$ Measurement were performed on photomicrographs $(\times 25)$ obtained from individual animal testis. Value represents the mean \pm SEM and there was no significant difference among means at $p<0.05$ by Duncan's multiple range test.

$\pm 0.09 \mathrm{~g} / \mathrm{d}, \mathrm{p}<0.0001)$. And this ethanol effect on body weight gain was maintained even with the intake of aspartate $(2.31 \pm 0.19$ vs $3.11 \pm 0.13 \mathrm{~g} / \mathrm{d}, \mathrm{p}<0.0001$, Figure 1) which was expected to have some affect on balancing in redox state. Contrasting to this, testis weight showed a trend in opposite direction - heavier testis in ethanol-fed groups. However, the difference of means did not reach statistical significance (Figure 1). When the cross-sectional area of seminiferous tubules of the rat testis was compared on hematoxylin and eosin stained sections, there were no significant differences among groups, and no significant effect of either ethanol or aspartate was observed (Table 2).

After ethanol and/or aspartate had been administered for 6 weeks, animals were sacrificed and the biochemical markers of liver function in serum were monitored. The activities of alkaline phosphatase and alanine aminotransferase, and the level of total cholesterol, total bilirubin, and diret bilirubin in serum were significantly greater $(p<0.0005,0.0001,0.050 .01$ and 0.05 , respectively) in the ethanol group. And aspartate treatment negated the effect of ethanol on the alkaline phosphatase activity returning to the normal control level. By 2-way ANOVA, ethanol, aspartate and the interaction effect were shown to be highly significant (Table 3). Other biochemical indices, however, were not significantly different among the groups (Table 3).

The TBARS levels in the rat testis homogenates were higher in the chronic ethanol group than the pair-fed control group $(0.50 \pm 0.04$ vs $0.41 \pm 0.01 \mathrm{nmol} / \mathrm{mg}$ protein, Figure 2). On the contrary, the aspartate treatment caused a marked reduction in testis TBARS level of the chronic ethanol group resulting in the level similar to the pair-fed control $(0.38 \pm 0.02$ vs $0.41 \pm 0.03 \mathrm{nmol} / \mathrm{mg}$ protein, Figure 2$)$.

On the other hand, the activities of the enzymes related to redox state in testis cytosol showed somewhat differ- 
Table 3. Effect of chronic ethanol consumption with or without aspartate on clinical serum variables of standard liver function test

\begin{tabular}{|c|c|c|c|c|c|c|c|}
\hline \multirow{2}{*}{ serum variables } & \multicolumn{4}{|c|}{ Groups } & \multicolumn{3}{|c|}{ Significance level of effect by 2 way ANOVA } \\
\hline & $\mathrm{CO}^{1)}$ & EO & CA & EA & Ethanol & Aspartate & Interaction \\
\hline $\mathrm{ALP}^{2}$ (units/l) & $244 \pm 35^{3, a)}$ & $456 \pm 34^{b)}$ & $265 \pm 15^{a)}$ & $270 \pm 21^{a)}$ & 0.0005 & 0.005 & 0.005 \\
\hline AST (units/l) & $173 \pm 10$ & $191 \pm 8$ & $184 \pm 13$ & $191 \pm 14$ & NS & NS & NS \\
\hline ALT (units/l) & $56 \pm 6^{a)}$ & $87 \pm 8^{b)}$ & $56 \pm 3^{\mathrm{a})}$ & $83 \pm 4^{\mathrm{b})}$ & 0.0001 & NS & NS \\
\hline $\mathrm{UA}(\mathrm{mg} / \mathrm{dl})$ & $2.5 \pm 0.2$ & $3.0 \pm 0.3$ & $2.5 \pm 0.2$ & $2.8 \pm 0.3$ & NS & NS & NS \\
\hline $\mathrm{CHO}(\mathrm{mg} / \mathrm{dl})$ & $72 \pm 5$ & $80 \pm 4$ & $70 \pm 2$ & $82 \pm 5$ & 0.05 & NS & NS \\
\hline $\mathrm{TP}(\mathrm{g} / \mathrm{dl})$ & $7.0 \pm 0.1$ & $7.3 \pm 0.2$ & $7.1 \pm 0.1$ & $6.7 \pm 0.5$ & NS & NS & NS \\
\hline TBIL (mg/dl) & $0.9 \pm 0.1^{\mathrm{ab})}$ & $1.2 \pm 0.1^{\mathrm{a})}$ & $0.8 \pm 0.1^{b)}$ & $1.1 \pm 0.1^{\mathrm{ab})}$ & 0.01 & NS & NS \\
\hline $\mathrm{DBIL}(\mathrm{mg} / \mathrm{dl})$ & $0.3 \pm 0.1^{a b)}$ & $0.5 \pm 0.0^{a)}$ & $0.2 \pm 0.0^{b)}$ & $0.5 \pm 0.1^{a)}$ & 0.005 & NS & NS \\
\hline LDH (units/l) & $5108 \pm 325$ & $4566 \pm 266$ & $4590 \pm 591$ & $4102 \pm 236$ & NS & NS & NS \\
\hline
\end{tabular}

1) Abbreviations used for treatments are as follows: $\mathrm{CO}=$ pair-fed control diet; $\mathrm{EO}=$ =ethanol diet; $\mathrm{CA}=$ pair-fed control diet + aspartate treatment; $\mathrm{EA}=\mathrm{ethanol}$ diet + aspartate treatment.

2) Abbreviations:ALP, alkaline phosphatase; AST, aspartate aminotransferase; ALT, alanine aminotransferase; UA, uric acid; CHO, chdesterol; TP, total protein; TBIL, total bilirubin; DBIL, direct bilirubin; and LDH, lactate dehydrogenase.

3) Each value represents the mean \pm SEM of 6 rats. Means with same superscript are not significantly different at $p<0.05$ by Duncan'smultiple range test.

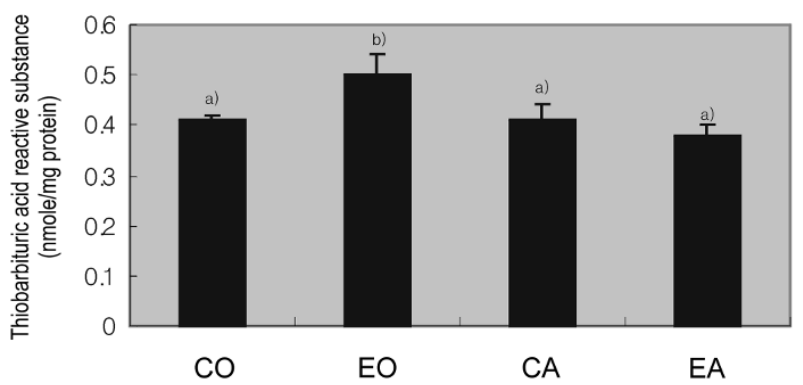

Figure 2. Effect of chronic ethanol administration with and without aspartate on ethanol-induced lipid peroxidation in testes. Thiobarbituric acid reactive substances in the testis were measured as an indicator of lipid peroxidation. Samples were $10 \%$ testis homogenate. Each value represents the mean \pm SEM of 6 rats. Means with same superscript are not significantly different at $p<0.05$ by Duncan's multiple range test. Abbreviations used for

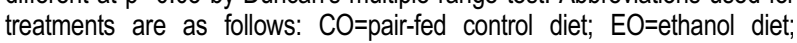

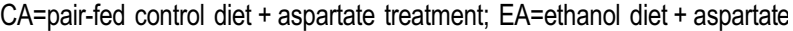
treatment.

ent result. Activities of glutathione peroxidase and glutathione reductase were not different among groups with a considerable decrease in glutathione reductase activity in ethanol-aspartate group. However, the activities of glucose-6-phosphate dehydrogenase and glutathione transferase were reduced in the chronic ethanol-groups suggesting a statistically significant ethanol effect (Table 4).

\section{Discussion}

Isocaloric substitution of carbohydrates by ethanol for 6 weeks resulted in a decreased weight gain in spite of similar food intake between ethanol and control groups (Figure 1), as reported before (Pirola and Lieber, 1975; Kawase et al., 1989). This energy deficit has been attributed to induction of microsomal ethanol oxidizing system, increased sympathetic tone and associated thermo-
Table 4. Effect of chronic ethanol administration with and without aspartate on free radical scavenging enzyme activities in rat testes

\begin{tabular}{|c|c|c|c|c|}
\hline \multirow{2}{*}{ Groups } & \multirow{2}{*}{$\mathrm{GPx}^{1}$} & GR & G6PDH & GST \\
\hline & & \multicolumn{3}{|c|}{ (nmoles/min/mg protein) } \\
\hline $\mathrm{CO}^{2)}$ & $172.5 \pm 9.1^{3)}$ & $36.7 \pm 1.7$ & $6.3 \pm 0.3^{\mathrm{ab})}$ & $1976.7 \pm 74.0^{\text {a) }}$ \\
\hline EO & $156.4 \pm 5.7$ & $37.7 \pm 1.0$ & $5.7 \pm 0.2^{\mathrm{ab})}$ & $1698.7 \pm 42.5^{\mathrm{b})}$ \\
\hline CA & $156.1 \pm 4.6$ & $35.9 \pm 1.1$ & $6.7 \pm 0.1^{a)}$ & $1888.0 \pm 49.7^{\mathrm{a})}$ \\
\hline EA & $144.8 \pm 7.6$ & $32.4 \pm 1.4$ & $5.5 \pm 0.4^{\mathrm{b})}$ & $1819.6 \pm 46.9^{\mathrm{ab})}$ \\
\hline \multicolumn{5}{|c|}{ Significance level of effect by 2-way ANOVA } \\
\hline Ethanol & NS & NS & 0.01 & 0.005 \\
\hline Aspartate & NS & 0.05 & NS & NS \\
\hline Interactior & NS & NS & NS & NS \\
\hline
\end{tabular}

1) Abbreviations: GPx, glutathione peroxidase; GR, glutathione reductase; G6PDH, glucose-6-phosphate dehydrogenase; GST, glutathione transferase.

${ }^{2)}$ Abbreviations used for treatments are as follows: $\mathrm{CO}=$ pair-fed control diet; $\mathrm{EO}=$ ethanol diet; $\mathrm{CA}=$ pair-fed control diet + aspartate treatment; $E A=e t h a n o l$ diet + aspartate treatment.

${ }^{3}$ Each value represents the mean \pm SEM of 6 rats. Means with same superscript are not significantly different at $p<0.05$ by Duncan's multiple range test.

genesis, and/or enhanced ATP breakdown (Cunningham and Spach, 1987; Lieber, 1994). The reduction of weight gain in the chronic ethanol group suggested the effective application of ethanol in this animal model. The administration of aspartate, however, did not restore the difference in weight gain due to ethanol.

The testis is known to be very vulnerable to chronic ethanol feeding, which leads to testicular atrophy (Van Thiel et al., 1979; Villalta et al., 1997). In this study, the chronic ethanol administration had a significant effect on the level of TBARS in testes of animals (Figure 2), as reported before (Rosenblum et al., 1985; 1987; 1989; Nordmann et al., 1990; Kashko et al., 1993; Bekpinar and Tugrul, 1995). Since the enhanced testicular lipid peroxidation is a metabolic consequence of chronic 
alcohol consumption, it can be assumed that the enhanced lipid peroxidation might be associated with ethanolinduced impairment of testicular function.

However, the morphological analysis of testis in the present experiment showed no significant differences between the chronic ethanol-fed and the pair-fed groups in terms of cross-sectional area of seminiferous tubules (Table 2). An observation that animals treated with the standard Lieber-DeCarli ethanol liquid diet for 50 days resulted in lowering of the testosterone production (Rosenblum et al., 1985), suggests sensitive nature of physiological functions of testis affected by an increase of lipid peroxides in the tissue without any apparent morphological alterations in the chronic ethanol group.

In our experiment, aspartate administration with ethanol normalized the lipid peroxidation in testes (Figure 2), indicating the possible interception by aspartate of ethanolinduced radical generation. Previously, we have shown that aspartate can restore the NADH/NAD ${ }^{+}$balance disturbed by ethanol oxidation in the liver and heart perfusion model (Park and Park, 1995; Park et al., 1997; Park et al., 1998) and suggested a probable mechanism of coupled reaction of aspartate aminotransferase and malate dehydrogenase in malate/aspartate shuttle. Accordingly, the modulation of cytoplasmic $\mathrm{NADH} / \mathrm{NAD}^{+}$ratio by aspartate might attenuate the NADH-dependent generation of ethanol-induced free radicals. The reduced level of lipid peroxides by aspartate in the chronic ethanol-fed rat testes suggested a biological effectiveness of aspartate against ethanol-driven disorders.

We also analyzed the capacity of testicular antioxidant defense system using glutathione after chronic ethanol feeding. The activities of glutathione peroxidase and glutathione reductase in the testis were not affected at all by chronic ethanol feeding (Table 4). However, there was a significant effect of ethanol (by 2-way ANOVA, $p<0.01)$ on decreasing the activity of glucose-6-phosphate dehydrogenase (Table 4). Since G6PDH can be inactivated by trans-4-hydroxy-2-nonenal (HNE), a known toxic product of membrane lipid peroxidation (Szweda et al., 1993), our result of lower G6PDH activity by ethanol which didn't reach statistical significance in group comparison could be related to the increased lipid peroxidation. Considering the physiological role of G6PDH in supplying NADPH for cytosolic GR and microsomal mixed-function oxidase system, there could be an inefficiency in coupling of GPx-GR for glutathione recycling possibly due to a limited supply of NADPH by G6PDH. Accordingly, the decrease in the activity of G6PDH by chronic ethanol administration may suggest a limitation in glutathione utilization in testes of ethanol-fed animals. Since the redox cycle of glutathione is important for the efficiency of glutathione-utilizing detoxification, the inhibition of the glutathione recycling enzyme would exacerbate the ethanol-induced oxidative stress. Chronic ethanol administration causes a significant depletion of GSH content in the testes (Rosenblum et al., 1985; 1987; 1989; Nordmann et al., 1990; Bekpinar and Tugrul, 1995) in contrast to liver tissue, where the metabolic adaptive system is in active operation (Oh et al., 1998). With the increased demand for testicular GSH during oxidative stress, forementioned depletion of GSH might enhance lipid peroxidation. Therefore, the reduction in contents of total glutathione as well as in glutathione recycling enzymic activities by chronic ethanol treatment would be responsible for, at least in part, the ethanol-induced oxidative tissue damages. The decrease in the activity of GST after chronic ethanol treatment might also impair the tissue detoxifying potential against oxygen free radicals (Table 4).

We earlier found no significant difference between chronic ethanol group and pair-fed control group in the indices of oxidative liver damage, namely, TBARS and carbonyl group content in contrast to testes tissue (Oh et al., 1998). This absence of oxidative liver damage in the ethanol group led us to postulate that chronic ethanol feeding has prompted the induction of strong radical scavenging activities in the liver tissues where rise in hepatic glutathione S-transferase was ensued. In contrast to liver tissues, GST activities were reduced in the testes of the chronic ethanol treatment. The aspartate supplementation to ethanol treatment partially resumed the GST activities, which might explain its protective effect in the testes from ethanol-induced oxidative damages (Table 4).

Toxic effects on testes elicited by ethanol treatment were reversed by 4-methylpyrazol, an inhibitor of alcohol dehydrogenase (Orpana, 1990). Inhibition of alcohol dehydrogenase catalysis likely prevents the accumulation of acetaldehyde and maintaining the same NADH/NAD ${ }^{+}$ ratio, comparable with those results obtained by aspartate treatment (Park et al., 1998). Thus, an increase in $\mathrm{NADH} / \mathrm{NAD}^{+}$ratio might have greatly contributed for the known toxic affect of alcohol on testes.

These results do indicate that aspartate supplementation to the ethanol feeding would protect the testes from the ethanol-induced oxidative damages by affecting the cellular redox potential. Even though pharmacological dose of vitamin $A$ had been suggested for testicular protection from ethanol-induced toxicity (Rosenblum et al., 1987), toxicity of long-term use of high dose vitamin A limits its general use. Therefore the aspartate should be considered as another protective agent of testes from chronic ethanol-driven peroxidative damage.

\section{Acknowledgement}

This work was supported by the grants from the Korea Research Foundation for Health Science and Seoul 
National University Hospital.

\section{References}

Bekpinar S, Tugrul Y. Influence of selenium supplementation in non-toxic doses on testes lipid peroxidation and antioxidant levels in chronic alcohol-fed rats. Alcohol-Alcohol 1995;30: $645-50$

Bradford $\mathrm{M}$. A rapid and sensitive method for the quantitation of microgram quantities of protein utilizing the principle of protein-dye binding. Anal Biochem 1970;72:240-54

Carberg I, Mannervick B. Glutathione reductase. In Methods in Enzymology, vol 113 (Fleisher, S. and Packer, L., eds.), 1985, 484-90, Academic Press, New York, NY

Cunningham CC, Spach PI. The effect of chronic ethanol consumption on the lipids in liver mitochondria. Ann NY Acad Sci 1987;492:181-92

Engerson TD, Mckelvey TG, Rhyne DB, Boggio EB, Snyder SJ, Jones HP. Conversion of xanthine dehydrogenase to oxidase in ischemic rat tissues. J Clin Invest 1987;79:1564-70

Harbig WH, Pabst MJ, Jakoby WB. Glutathione S-transferase. J Biol Chem 1985;249:7130-39

Kashko MF, Khokha AM, Antsulevich SN, Doroshkevich NA, Voronov PP. Influence of ethanol and ethanol-induced lipid peroxidation on the steroidogenic activity of testicles. UkrBiokhim-Zh 1993;65:89-94

Kawase T, Kato S, Lieber CS. Lipid peroxidation and antioxidant defense system in rat liver after chronic ethanol feeding. Hepatology 1989;10:815-21

Lee GL. Manual of histopathologic staining methods of the Armed Forces Institute of Pathology, $3^{\text {rd }}$ ed., 1960, 12-20, Mcgraw-Hill Book company, New York, NY

Lieber CS. Alcohol and liver: 1994 update. Gastroenterology 1994;106:1085-5

Löhr WG, Waller HD. Glucose-6-phosphate dehydrogenase. In Method of Enzymatic Analysis (Bergmeyer, H.U., ed.), 1974, 636-43, Academic press, New York and London

Nordmann R, Ribiere C, Rouach H. Ethanol-induced lipid peroxidation and oxidative stress in extrahepatic tissue. Alcohol Alcohol 1990;25:231-37

Oh SI, Kim Cl, Chun HJ, Park SC. Chronic ethanol consumption affects glutathione status in rat liver. J Nutr 1998;128:75863
Orpana AK, Orava MM, Vihko RK, Harkonen M, Eriksson CJ. Role of ethanol metabolism in the inhibition of testosterone biosynthesis in rats in vivo: importance of ganadotropin stimulation. J Steroid Biochem Mol Biol 1990;37:273-78

Park JW, Chun YS, Kim MS, Park YC, Kwak SJ, Park SC. Metabolic regulation of cellular redox potential can improve cardiac recovery from ischemia-reperfusion injury. Int $\mathrm{J}$ Cardiol 1998;65:139-47

Park YC, Oh SI, Park YH, Park SC. Modulation by aspartate of ischemia/reperfusion-induced oxidative stress in rat liver. Exp Mol Med 1997;29:19-23

Park YC, Park SC. Reduction of oxidative stress by aspartate in the ethanol-perfused rat liver tissues. Kor J Biochem 1995; 27:165-69

Peltola V, Huhtaniemi I, Ahotupa M. Antioxidant enzyme activity in the maturing rat testis. $\mathrm{J}$ androl 1992;13:450-55

Pirola RC, Lieber CS. Energy wastage in rat given drugs that induce microsomal enzymes. J Nutr 1975;105:1544-48

Rosenblum ER, Gavaler JS, Van Thiel DH. Lipid peroxidation: a mechanism for ethanol-associated tesicular injury in rats. Endocrinology 1985;116:311-18

Rosenblum ER, Gavaler JS, Van Thiel DH. Vitamin A at pharmacologic doses ameliorates the membrane lipid peroxidation injury and testicular atrophy that occurs with chronic alcohol feeding in rats. Alcohol Alcohol 1987;22:241-49

Rosenblum ER, Gavaler JS, Van Thiel DH. Lipid peroxidation: a mechanism for alcohol-induced tesicular injury. Free Radic Biol Med 1989;7:569-77

Szweda LI, Uchida K, Tasi L, Stadtman ER. Inactivation of glucose-6-phosphate dehydrogenase by 4-hydroxy-2-nonenal. J Biol Chem 1993;268:3342-47

Tappel AL. Glutathione peroxidase and hydroperoxides. In Methods in Enzymology, vol. 52 (Fleisher, S. and Parker, L., eds.), 1978, 506-13, Academic Press, New York, NY

Uchiyama M, Mihara M. Determination of malonaldehyde precusor in tissues by thiobarbituric acid test. Anal Biochem 1978;86:271-78

Van Thiel DH, Gavaler JS, Cobb CF, Sherins RJ, Lester R. Alcohol-induced testicular atrophy in the adult male rat. Endocrinology 1979;105:888-95

Villalta J, Ballesca JL, Nicolás JM, Martinez de Osaba MJ, Antunez E, Pimentel C. Testicular function in asymptomatic chronic alcoholics: relation to ethanol intake. Alcohol Clin Exp Res 1997;21:128-33 